\title{
Jerusalem artichoke (Helianthus tuberosus L.) productivity in different Italian growing areas: a modelling approach
}

\author{
Mario Baldini, ${ }^{1}$ Francesco Danuso, ${ }^{1}$ Alvaro Rocca, ${ }^{1}$ Elena Bulfoni,, Andrea Monti, ${ }^{2}$ \\ Giuseppe De Mastro ${ }^{3}$ \\ ${ }^{1}$ Dipartimento di Scienze Agrarie e Ambientali, Università di Udine; ${ }^{2}$ Dipartimento di Scienze \\ Agro-Ambientali, Università di Bologna; ${ }^{3}$ Dipartimento di Scienze Agro-Ambientali e Territoriali, \\ Università di Bari, Italy
}

\begin{abstract}
Jerusalem artichoke is considered one of the most interesting crops for inulin production. It has been used to date for the production of low calorie sweetening syrups, dietetic food enriched with fibre, medicines and cosmetics, while more recently, interesting prospects have been opening up for energy uses. The main aspects influencing its adaptability to different pedo-climatic conditions and cropping systems were analysed by implementing CSS (Cropping System Simulator, a simulation model describing crop biomass production) for this specific crop. Growth analysis experimental data of plant dry matter accumulation, obtained over two years of trials (1999-2000) in different Italian growing areas (Udine, Bologna, Bari) under irrigated and rain-fed conditions, were used for the parameterisation and calibration of the model. The biomass accumulation observed and simulated under rain-fed and irrigated conditions in the different growing areas is reported for the different plant organs, with good correspondence shown between simulated and measured values as reported by the statistical indices for the model calibration, particularly for biomass of tubers and leaves. The model studied, despite a simplified description of some processes,
\end{abstract}

Correspondence: Mario Baldini, Dipartimento di Scienze Agrarie e Ambientali, Università di Udine, via delle Scienze 208, 33100 Udine, Italy. Tel. +39.0432.558600 - Fax: +39.0432.558603.

E-mail: baldini@uniud.it

Key words: Jerusalem artichoke, Crop model, Calibration, Biomass production.

Acknowledgements: field trials were conducted within the framework and with the financial support of the miur prin 1999 Project Colture per la produzione di inulina: modelli di risposta ambientale e strategie colturali, while crop model development has been possible thanks to the Projects Filiere agroenergetiche in Friuli Venezia Giulia: valutazione della sostenibilità economica, energetica e ambientale a livello aziendale e territoriale, which were funded by the Friuli Venezia Giulia Region, ex art 17, LR n.26, 10/11/2005.

Received for publication: 16 November 2010.

Accepted for publication: 2 April 2011

(C) Copyright M. Baldini et al., 2011

Licensee PAGEPress, Italy

Italian Journal of Agronomy 2011; 6:e20

doi:10.4081/ija.2011.e20

This work is licensed under a Creative Commons Attribution NonCommercial 3.0 License (CC BY-NC 3.0). proves to represent the maximum biomass yield of Jerusalem artichoke satisfactorily, with an adequate response to the main environmental factors causing yield and biomass production variation among the years and locations. However, further model improvements are necessary in order to better represent the relationship between phenology and translocation of the assimilates between stalk and tuber during the development phases of the plant, suggesting shorter survey intervals over this growing phase.

\section{Introduction}

Jerusalem artichoke can be considered as both a sugar and dietary fibre crop, as it accumulates linear polymers of fructose (fructans, also known as inulin) in its roots, tubers and stalks, with a highly variable degree of polymerisation (4-150 DP), which affects their end-use. Fructans with low DP and fructose, obtained by hydrolysis of the fructans, are often used directly as dietary fibres or as low-calorie sweetening syrups, while inulin with high DP (10-30) is used entirely for industrial and non-food uses such as pharmaceuticals and cosmetics (Fuchs, 1993; Danuso, 2001). One of the main problems of today's sugar processing industry is the need to extend the harvest season, in particular by anticipating it, with compensation given to farmers for the lower yield of earlier harvests, as in Belgium where the industry pays a higher price to compensate for this lower production (Danuso, 2001).

Jerusalem artichoke is relegated today to small areas mainly for the production of tubers for human or livestock consumption, so there could be interesting prospects for high earning potential with an early whole-plant harvest (stalks plus tubers); however, there are still problems connected to the perfecting of harvest machinery and processing methods (Baldini et al., 2006). The whole-plant harvesting method has always produced higher yields than the traditional harvesting of tubers alone, with the agronomic advantage of freeing the land earlier (Paolini et al., 1996; Baldini et al., 2004). The crop can be cultivated as: i) an annual crop, with the harvest of stalks and tubers together, or ii) a multi-year crop, with only the aerial biomass harvested each year (D'Egidio et al., 1998; Baldini et al., 2006). These considerations and the current need to find new renewable energy sources open new prospects for Jerusalem artichoke as a biomass crop for energy uses, particularly for liquid biofuel production (bioethanol; Curt et al., 2006), methane from anaerobic digestion (Lehtomaki et al., 2008) and gas from pyrolysis (Encinar et al., 2009).

A more detailed understanding of the distribution of assimilates during plant growth among different organs becomes necessary in order to predict, through scenario analysis and simulation experiments, growth and production of stems and tubers depending on 
pedo-climatic conditions, cropping techniques and genetic material. This may be particularly useful in analysing the feasibility of such possible crop uses in different environments. For this reason, the aim of our study was the improvement and calibration of the Cropping System Simulator (CSS) model (Danuso et al., 1999) to enable it to simulate Jerusalem artichoke productivity in different conditions (different Italian growing areas). CSS, in fact, has already been parameterised and calibrated with encouraging results for the most common annual crop (Danuso et al., 2009). CSS is a generic crop simulation model implemented with the Simple Easy to use Modelling Language (SEMoLa) software, an application for the development of simulation models and agro-ecological knowledge integration (Danuso, 2003). Both SEMoLa and CSS have been developed and are maintained at the Department of Agricultural and Environmental Sciences of the University of Udine, Italy. The calibration performed in our study has been done using data obtained from experimental trials conducted in different Italian areas within the framework of the PRIN Project (MIUR), entitled Colture per la produzione di inulina: modelli di risposta ambientale e strategie colturali.

\section{Materials and Methods}

\section{Experimental trials}

Trials on Jerusalem artichoke (Helianthus tuberosus L., variety Violet de Rennes) were conducted over the two years 1999 to 2000, by the Working Groups taking part in the PRIN project, in three areas of Italy: Udine, Policoro-Bari and Cadriano-Bologna (Table 1). In each environment, the effects of two different production factors were evaluated: time of harvest and irrigation regime with two treatments: i) replacement of total evapo-transpiration and ii) dry regime (rainfed crop with the aid of irrigation).

Tubers (average weight 50-70 g each) where manually planted at a depth of $3-4 \mathrm{~cm}$, in rows $0.7 \mathrm{~m}$ apart and with a distance between plants in the row of $0.25 \mathrm{~m}$ ( $0.20 \mathrm{~m}$ in Bologna), giving a planting density of 5.7 tubers $/ \mathrm{m}^{2}$ in Bari and Udine and 7 tubers $/ \mathrm{m}^{2}$ in Bologna. The trial design was a split-plot with four replications. The experimental unit was 5 rows of $12 \mathrm{~m}$ in length in Bologna, giving an area of $42 \mathrm{~m}^{2}$, and 8 rows, $8 \mathrm{~m}$ long in Udine and Bari for an area of 44.8 $\mathrm{m}^{2}$. Dry matter accumulation was evaluated after collecting, by hand, five plants at different plant phenological phases for each plot, covering the total growing season until the standing crop was dried naturally. In particular, the number of samplings varied from 6 to 11 , depending on the different locations, with about 10-15 days between two consecutive harvests. At each sampling, the fresh and dry weights of leaves, stems (with ramifications) and tubers (without stolons) were measured.

\section{Model implementation}

CSS is a generic simulator of the cropping system, with a daily time step, already used for forecasting and risk evaluation in different cropping areas (Danuso et al., 2009). The model has been implemented by the SEMoLa language (version 5.8; Danuso, 2003), which can be compiled in different ways in order to produce stand-alone executable programmes. CSS is freely available as source code written in the SEMoLa language or as an executable program. An important characteristic of this model is that, because it is created with this language, it can be modified and updated very easily.

CSS is formed by interconnected modules that simulate soil water balance (using a simple two-layer cascade method), nitrogen dynamics, crop phenology and growth as affected by environmental, pedological and agricultural factors (Figure 1). It is a generic model because the same equation structure allows the simulation of different crops (e.g. wheat, maize, soybean) in relation to crop parameters that have to be specifically calibrated. It consists of different sub-models (modules), among which the most relevant to crop production is CSS_CropYield, which simulates crop phenology (growing phases depending on growing degree, days accumulation and day length), aerial and root biomass (Wroot), crop yield and leaf area dynamics [based on the Simple and Universal CROp growth Simulator (SUCROS) model; van Laar et al., 1997]. The aerial biomass (or crop biomass, Wcrop) is partitioned in leaves (Wleav), stalks (Wstem) and storage organs (Wstor). CSS_CropYield describes the growth from photosynthesis and respiration, and allocates the daily dry matter increments to the different organs according to the partitioning factors introduced as a function of the development stage of the crop.

Soil is considered as divided into two layers (Figure 2). The depth of the upper layer (Dr, root layer) changes, according to the crop root growth, from the sowing depth to the maximum depth exploitable by the roots during the crop cycle (Ds). The soil layer between the rooting depth and maximum exploitable soil depth is the deep layer (Dd), maximum at crop sowing and decreasing as the crop roots continue growing. The maximum depth that can be reached by the root system depends on the crop characteristics, the presence of compact layers, gravel, rocks, or shallow water table.

CSS simulates drainage to the water table and capillary rise from it, according to Driessen and Konijn (1992). If the depth of the

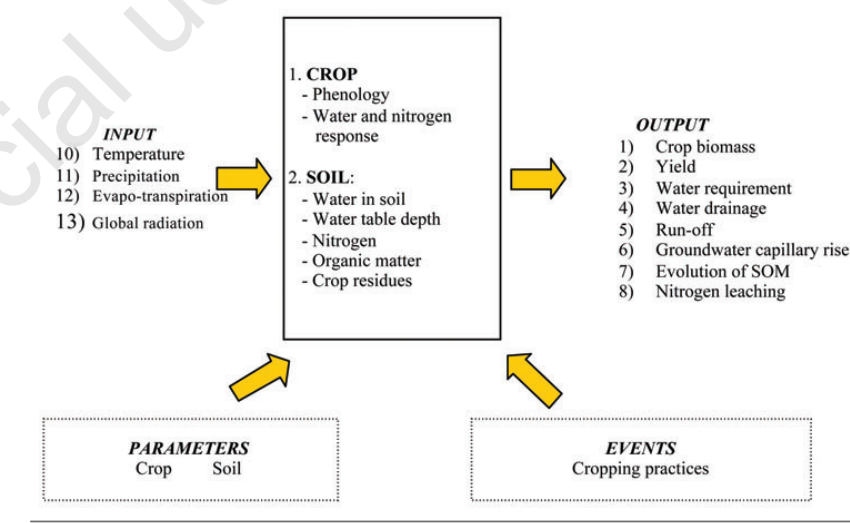

Figure 1. General structure of the Cropping System Simulator model.

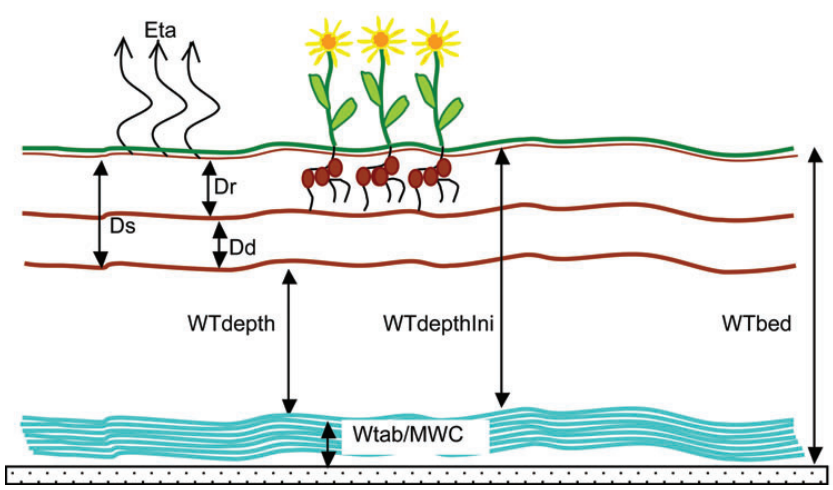

Figure 2. Soil layers as described by the Cropping System Simulator (CSS) model. Eta, evapo-transpiration; Dr, depth of the root layer; Ds, soil depth by roots; Dd, depth of the deep layer; WTdepth, water table depth; WTdepthIni, initial water table depth; Wtab/MWC, depth of water table/maximum water content; WTbed, depth of water table bed. 
phreatic water table bed is known, it also gives a simple simulation of the dynamics of water table depth.

Crop residue decay produces new humus and mineral compounds; they are divided into easily decomposable residues and those resistant to decomposition, with different mineralisation and humus synthesis coefficients. Soil microbial biomass is also considered. The balance of soil organic matter and residues is simulated, for the working layer, by an implementation of the RothC model (Coleman and Jenkinson, 2008).

The CSS model has been modified in order to improve its capacity to represent crops like Jerusalem artichoke or potato, in which the translocation of assimilates from stalks to tubers, at the end of the cycle, is relevant. This is a specific physiological process not existing in grain crops like maize or wheat. The decreasing of leaves and stem weight at the late growth stages owing to senescence and translocation has been described in CSS through two interrelated aspects: i) no more biomass is allocated to leaves and stems after the physio logical maturity stage and ii) part of their biomass is lost through senescence while the rest is translocated to tubers.

\section{Model parameterisation and calibration}

In our study, CSS has been parameterised and calibrated for the Jerusalem artichoke by comparing the simulation results for biomass accumulation (t/ha dry matter) in the different plant organs (leaf, stem and storage organ) with the experimental data obtained in the different locations. The first step of the parameterisation procedure has been done using information from previous research, common knowledge and experience; the second step with a trial-and-error procedure. The last step, for a more accurate calibration, has been performed using the automatic calibration routine of the SEMoLa software that uses an iterative procedure (Gauss-Newton linearisation method; Beck and Arnold, 1977; Draper and Smith, 1981) for the minimisation of the residual sum of squares between simulated and

Table 1. Working groups and locations of the experimental sites.

\begin{tabular}{|c|c|c|c|c|}
\hline Working groups & Locations & $\begin{array}{l}\text { Altitude } \\
\text { m a.s.l. }\end{array}$ & Latitude & Longitude \\
\hline University of Udine & Udine (UD) & 110 & $46^{\circ} 03^{\prime} \mathrm{N}$ & $13^{\circ} 13^{\prime} \mathrm{E}$ \\
\hline University of Bologna & Cadriano (BO) & 33 & $44^{\circ} 30^{\prime} \mathrm{N}$ & $11^{\circ} 20^{\prime} \mathrm{E}$ \\
\hline University of Bari & Policoro (BA) & 31 & $40^{\circ} 20^{\prime} \mathrm{N}$ & $16^{\circ} 70^{\prime} \mathrm{E}$ \\
\hline
\end{tabular}

Table 2. Values of the soil parameters measured in the different sites and adopted to run the Cropping system simulator model.

\begin{tabular}{|c|c|c|c|c|}
\hline Name & Soil parameter & $\begin{array}{c}\text { Cadriano } \\
\text { (B0) }\end{array}$ & $\begin{array}{l}\text { Policoro } \\
\text { (BA) }\end{array}$ & $\begin{array}{r}\text { Udine } \\
\text { (UD) }\end{array}$ \\
\hline Gravel & Gravel volumetric content, $\%$ & 0 & 0 & 15 \\
\hline Sand & Sand content, \% & 37 & 40 & 43 \\
\hline Clay & Clay content, $\%$ & 18 & 23 & 17 \\
\hline $\mathrm{OM}$ & Organic matter, $\%$ & 1.3 & 3.6 & 2.9 \\
\hline $\mathrm{CaCO}_{3}$ & Total carbonates, $\%$ & 1 & 6 & 3 \\
\hline Ds & Max exploitable soil depth by roots, $\mathrm{mm}$ & 3000 & 2500 & 500 \\
\hline MWC & Max water content fine fraction, $\mathrm{mm} / \mathrm{mm}$ & 0.5 & 0.58 & 0.56 \\
\hline $\mathrm{FC}$ & Field capacity, mm/mm & 0.26 & 0.38 & 0.31 \\
\hline WP & Wilting point, mm/mm & 0.12 & 0.14 & 0.15 \\
\hline Dw & Soil working depth, mm & 400 & 400 & 400 \\
\hline Wtbed & Depth of the water table bed, mm & 20,000 & 20,000 & 60,000 \\
\hline Wtdepth & Initial depth of the water table, $\mathrm{mm}$ & 2500 & 2000 & 40,000 \\
\hline
\end{tabular}

observed data.

This procedure was carried out by setting several multiple simulations for each scenario, following the real situation (pedo-climatic conditions and cropping practices) in the experimental trials for each location and thesis. To avoid the influence of crop parameters on calibration, they have been changed or fixed together for all scenarios.

\section{Input data for simulations}

To perform simulations, CSS requires meteorological data, soil parameters, crop parameters and parameters for the cropping scenario to be represented (Figure 1). These data have to be organised into four types of input data files: exofile containing exogenous variables (meteorological data), parfile with soil and crop parameters, evtfile declaring time, type and modality of every cropping practice (events) and actfiles (one for each event type), containing the actions or parameters of each application of cropping techniques. At run-time and before the beginning of the simulation, parameter values of the parfile are set and their values usually remain the same throughout the simulation; however, their values can be changed during the crop cycle by the event instances of the evtfile; these instances make ref-

Table 3. General crop parameters of the Cropping system simulator.

\begin{tabular}{|c|c|c|c|}
\hline Parameter & Description & Value & Estimation \\
\hline AEffCoef & $\begin{array}{l}\text { Potential assimilation efficiency } \\
\text { coefficient, } \mathrm{gCO}_{2} / \mathrm{MJ}\end{array}$ & 8 & $\mathrm{~L}^{\circ}$ \\
\hline AlloWS & Allowed water stress & 0.2 & $\mathrm{~L}^{\circ}$ \\
\hline CNcrit & \multicolumn{2}{|c|}{ Critical Nitrogen concentration in plant, kgN/t0.65 } & $\mathrm{L}^{\circ}$ \\
\hline CoefEst & Light extinction coefficient & 0.8 & $\mathrm{C}$ \\
\hline ConvLeCo & $\begin{array}{l}\text { Conversion of } \mathrm{CH}_{2} \mathrm{O} \text { to leaf biomass, } \\
\mathrm{t} / \mathrm{tCH}_{2} \mathrm{O}\end{array}$ & 0.59 & $\mathrm{~L}^{\circ}$ \\
\hline ConvRoCo & $\begin{array}{l}\text { Conversion of } \mathrm{CH}_{2} \mathrm{O} \text { to root biomass, } \\
\mathrm{t} / \mathrm{tCH}_{2} \mathrm{O}\end{array}$ & 0.71 & $\mathrm{~L}^{\circ}$ \\
\hline ConvSmCo & $\begin{array}{l}\text { Conversion of } \mathrm{CH}_{2} \mathrm{O} \text { to stem biomass, } \\
\mathrm{t} / \mathrm{tCH} \mathrm{H}_{2} \mathrm{O}\end{array}$ & 0.75 & $\mathrm{~L}^{\circ}$ \\
\hline ConvSrCo & $\begin{array}{l}\text { Conversion of } \mathrm{CH}_{2} \mathrm{O} \text { to storage } \\
\text { organs biomass, } \mathrm{t} t \mathrm{tCH}_{2} \mathrm{O}\end{array}$ & 0.71 & $\mathrm{~L}^{\circ}$ \\
\hline CRnc & Nitrogen content in crop residue, $\mathrm{kgN} / \mathrm{kg}$ & 0.004 & $\mathrm{~L}^{\circ}$ \\
\hline Dsow & Sowing depth, mm & 90 & A \\
\hline FracResDPM & Fraction of DPM in crop residues & 0.6 & $L^{\#}$ \\
\hline LAIc & Critical leaf area index for stress & 3.5 & C \\
\hline MDRWat & Maximum leaf death rate for water stress & 0.03 & $\mathrm{~L} / \mathrm{C}$ \\
\hline Qsow & Seed sowing amount, t ha/d & 0.7 & A \\
\hline Rmax & Maximum root deepening rate, $\mathrm{mm} /{ }^{\circ} \mathrm{C} / \mathrm{d}$ & 1.3 & $L^{\#}$ \\
\hline Sls & Specific leaf surface, haLeaf/t & 2.5 & $\mathrm{~L}^{\circ}$ \\
\hline Taefl & $\begin{array}{l}\text { Minimum temperature for } \mathrm{CO}_{2} \\
\text { assimilation, }{ }^{\circ} \mathrm{C}\end{array}$ & 5 & $\mathrm{~L} / \mathrm{C}$ \\
\hline Taef2 & $\begin{array}{l}\text { Temperature for } 25 \% \text { opt. } \mathrm{CO}_{2} \\
\text { assimilation, }{ }^{\circ} \mathrm{C}\end{array}$ & 10 & $\mathrm{~L} / \mathrm{C}$ \\
\hline Taef3 & $\begin{array}{l}\text { Minimum optimal temperature for } \mathrm{CO}_{2} \\
\text { assimilation, }{ }^{\circ} \mathrm{C}\end{array}$ & 15 & $\mathrm{~L} / \mathrm{C}$ \\
\hline Taef4 & $\begin{array}{l}\text { Maximum optimal temperature for } \mathrm{CO}_{2} \\
\text { assimilation, }{ }^{\circ} \mathrm{C}\end{array}$ & 38 & $\mathrm{~L} / \mathrm{C}$ \\
\hline Taef5 & $\begin{array}{l}\text { Maximum temperature for } \mathrm{CO}_{2} \\
\text { assimilation, }{ }^{\circ} \mathrm{C}\end{array}$ & 45 & $\mathrm{~L} / \mathrm{C}$ \\
\hline Tbase & Base temperature for development, ${ }^{\circ} \mathrm{C}$ & 9 & $\mathrm{~L} / \mathrm{C}$ \\
\hline Ync & Nitrogen content in yield, kgN/kg & 0.005 & $\mathrm{~A}$ \\
\hline
\end{tabular}

The values adopted and calibrated for the simulation of the Jerusalem artichoke crop are reported; the estimation method is indicated: from literature (L), calibrated against experimental results of crop biomass (C) and from common agricultural knowledge (A); ${ }^{\circ}$ from SUCROS (Simple and Universal CROp growth Simulator); ${ }^{\sharp}$ from a previous study of CSS calibration (Danuso et al., 1999); DPM, decomposable plant material. 
erence to specific sets of parameter values in the corresponding actfile and then immediately modify the current parameter values. The modifications of the parameter values by events are considered the actions of the event; in this case, parameters act in the system like switches. For example, the simulation can start with the crop parameters for fallow; when the event Planting occurs, all the crop parameters (for phenology, light interception, growth, etc.) are changed, depending on the sown/planted crop. This allows the simulation of crop rotations with different types and amounts of crop inputs. Every event type of the evtfile has a related actfile, which contains various sets of parameters for the different application modes of the event. The user (and not just the modeller) can also change and increase the number of parameter sets in actfiles. In the case of organic fertilisation, the event OrgFert has the actfile OrgFert.act, which contains parameter sets specifying the characteristics of different organic fertilisers like manure, straw, slurry, etc.

\section{Meteorological data}

The daily meteorological data required in CSS to run simulations are minimum and maximum air temperatures $\left({ }^{\circ} \mathrm{C}\right)$, precipitation $(\mathrm{mm} / \mathrm{d})$, reference evapo-transpiration $(\mathrm{mm} / \mathrm{d})$ and global radiation $\left(\mathrm{MJ} / \mathrm{m}^{2} / \mathrm{d}\right)$, which are saved in exofile. These data have to be complete and without outliers; to avoid this problem, meterological data have been checked using Climatica software (Danuso and Sandra, 2006), which assists in the creation of the correct meteorological data file by automatic correction of the names of variables, changes the date format, and rebuilds missing data. It also advises when files are not correct for missing days, wrong time order and data out of range. The model calibration has been performed using the historical meteorological data corresponding to the years of the trials (1999-2000) in the three localities. The trends of maximum and minimum temperature and rainfall reported in Figure 3 show the different meteorological conditions.

\section{Soil and crop parameters}

The main soil characteristics measured for each site and used for the simulations are given in Table 2. The soil in Udine was very shallow (about $50 \mathrm{~cm}$ ) and without groundwater useful for the crops, while in both Bologna and Bari the contribution of groundwater was important. According to the specific crop selected, crop parameter values were adjusted considering a reasonable range of variation, as dictated by previous research, knowledge or experience. A list of the crop parameters resulting from the parameterisation and used for the final simulations is reported in Tables 3 and 4. This information about soil and crops was used to customise the parameter files (parfile).

\section{Crop management simulation}

In CSS the cropping techniques are considered as events; that is, as phenomena that happen and instantaneously modify parameters and states of the system. At present, the following events can be selected to build cropping scenarios: planting, organic and mineral fertilisation, irrigation, harvesting, residue chopping, harrowing, hoeing, extirpation, chiselling and ploughing. The sequences of cropping techniques are saved in event files (evtfiles). The agronomic techniques adopted during experimental trials are inserted in the evtfiles to perform the simulation (Tables 5 and 6).

\section{Results}

The agronomical results for the Jerusalem artichoke obtained in the two years of trials, about yield and biomass accumulation for the different crop organs, emphasise that in Bologna, thanks to the good pedo-climatic characteristics, irrigation appeared superfluous. The highest production of the entire research project was obtained corresponding to a very late harvest time; for the final yield of Jerusalem artichoke tubers, the Bari environment was the most productive. This crop adapts well to a hot arid climate, such as that in the south of Italy, on condition that the limited water availability is compensated for by good soil depth and a water table within reach of the exploratory capacities of its root apparatus (Baldini et al., 2006). The integration of the specific algorithm in CSS in order to represent transloca-
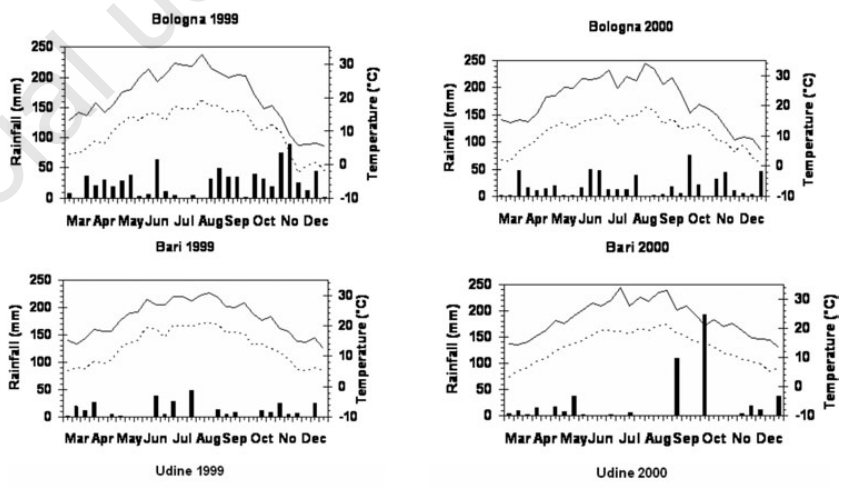

Udine 2000
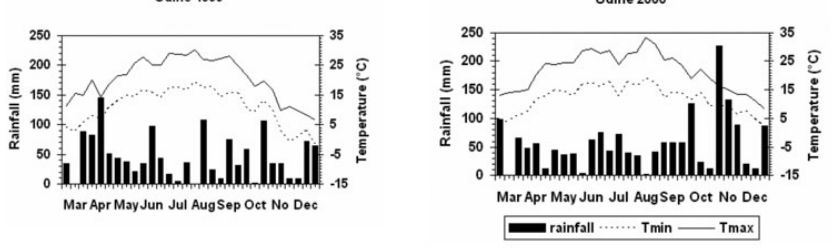

Figure 3. Ten-day total rainfall, and maximum and minimum temperatures at the experimental sites during 1999 and 2000.

Table 4. Crop parameters of the Cropping System Simulator related to the development stage of the crop.

\begin{tabular}{|c|c|c|c|c|c|c|c|c|}
\hline Parameter & Symbol & Emergence & $\begin{array}{l}\text { Complete } \\
\text { soil coverin }\end{array}$ & $\begin{array}{l}\text { End vegetative } \\
g \text { phase }\end{array}$ & $\begin{array}{c}\text { Start } \\
\text { accumulation }\end{array}$ & $\begin{array}{l}\text { Physiological } \\
\text { maturity }\end{array}$ & $\begin{array}{l}\text { Harvest } \\
\text { maturity }\end{array}$ & $\begin{array}{c}\text { Estimation } \\
\text { method }\end{array}$ \\
\hline Growing degree days & GDD & 90 & 490 & 900 & 1200 & 2400 & 3000 & $\mathrm{C}$ \\
\hline Crop coefficients for water use & $\mathrm{Kc}$ & 0.35 & 0.6 & 1 & 1 & 0.35 & - & $\mathrm{L}^{\circ}$ \\
\hline Optimal Nitrogen concentration & No & 20 & 20 & 12 & 10 & 8 & - & $\mathrm{L} / \mathrm{C}$ \\
\hline Growth fraction leaves/shoots & LF & 0.6 & 0.4 & 0.3 & 0.15 & 0.1 & - & $\mathrm{C}$ \\
\hline Growth fraction stem/shoots & SF & 0.4 & 0.6 & 0.7 & 0.8 & 0.4 & - & $\mathrm{C}$ \\
\hline Total growth fraction roots & $\mathrm{RF}$ & 0.05 & 0.05 & 0.01 & 0.01 & 0 & - & C \\
\hline
\end{tabular}

For each parameter, values have to be inserted, corresponding to the following stages: plant emergence from soil, complete soil covering, end of vegetative phase, start of accumulation in storage organs, physiological maturity and harvest maturity. During simulation, the current values for these parameters are obtained by linear interpolation among these values and as a function of current value of accumulated GDD; the estimation method is indicated: from the literature (L), calibrated against experimental results of crop biomass (C); ${ }^{\circ}$ from FAO (Allen et al., 1998). 
tion of assimilates from stalks to tubers was necessary because this specific physiological process is typical of this crop. Results demonstrate that this model adjustment does improve the simulation results especially in the last phase of the crop growth. Despite this model improvement to estimate a better distribution of biomass in the storage organs, further ameliorations are desirable especially considering the physiological factors.

The most relevant results of this study concern the model calibration, which led to good simulation results. In Figures 4 and 5, the biomass accumulation observed and simulated under rain-fed and irrigated conditions is reported for the different plant organs, where good correspondence between simulated and measured values is noted, particularly for biomass of tubers and leaves. In stalks, the simulated accumulation trend turns out to be slightly more advanced in comparison with that obtained experimentally. An inexact representation of the timing of storage of assimilates by the stems and the further reallocation of the storage reserves to the tuber when growing rapidly can be observed.

Differences observed between measured and simulated data for biomass accumulation in tubers during the last growing phase in Udine and Bologna in 1999 could be explained with the quick physiological changes owing to climatic variations. In fact, in October and November of 1999, a sudden temperature decrease corresponding to the last harvest times can be observed (Figure 3). This fact could have triggered a translocation rate increase, accelerating the remobilisation of reserves from stalks to tubers. This becomes more evident when the harvest was delayed in Bologna during the first year. These results emphasise the difficulties found in survey methodology and model implementation to represent these particular physiological adaptations, suggesting shorter survey intervals during this growing phase, when the translocation rate is increasing. On the other hand, comparing the total biomass accumulation for Jerusalem artichoke in the different growing areas, during the same crop season and under rain-fed conditions (Figure 6), it is evident that the model is able to
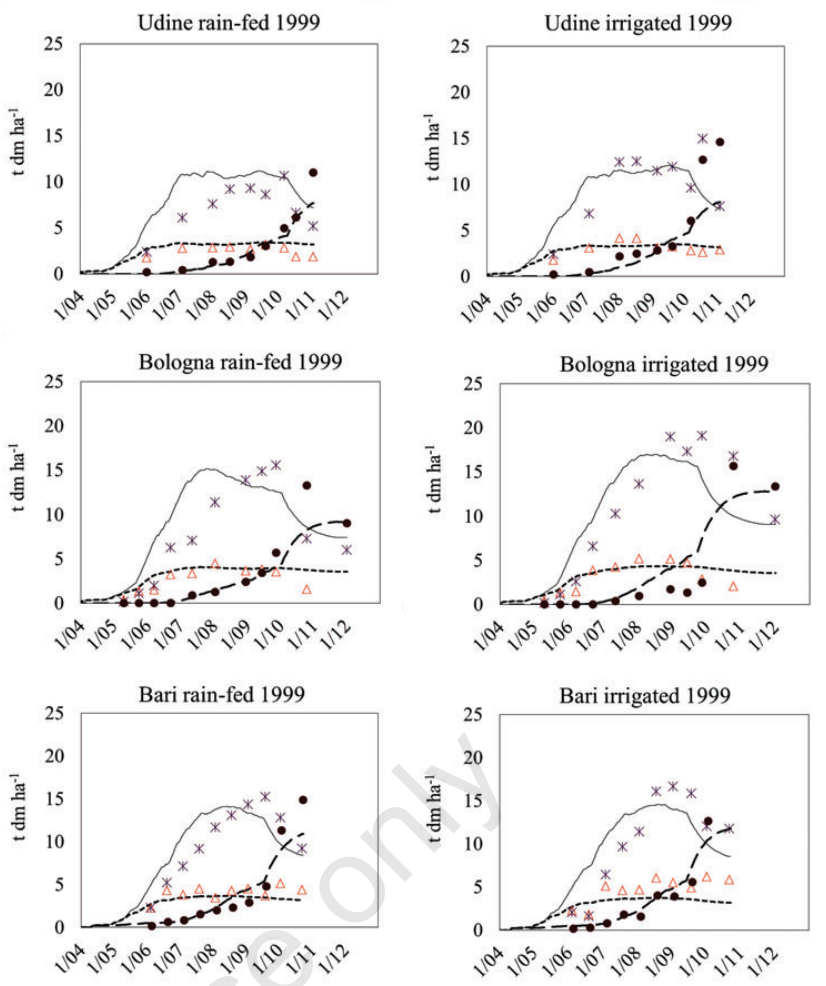

Figure 4. Leaves, stalks and storage organs biomass accumulation, as simulated by the Cropping System Simulator (CSS), in comparison with the experimental growth data for the three locations and the two irrigation regimes (year 1999). _ stems d.m. weight simulated; --_- leaves d.m. weight simulated; _ _ storage organs d.m. weight simulated; * stems d.m. weight measured; $\Delta$ leaves d.m. weight measured; • storage organs $\mathrm{d}$.m. weight measured.

Table 5. Main cropping management techniques adopted for Jerusalem artichoke.

\begin{tabular}{|c|c|c|c|c|c|c|}
\hline & Bari, 1999 & Bari, 2000 & Bologna, 1999 & Bologna, 2000 & Udine, 1999 & Udine, 2000 \\
\hline Soil tillage & $\begin{array}{l}\text { Ploughing at } 40 \mathrm{~cm} \text {, } \\
\text { harrowing (2) }\end{array}$ & $\begin{array}{l}\text { Ploughing at } 40 \mathrm{~cm} \text {, } \\
\text { harrowing (2) }\end{array}$ & $\begin{array}{l}\text { Ploughing at } 30 \mathrm{~cm} \text {, } \\
\text { harrowing, } \\
\text { pre-planting puckering }\end{array}$ & $\begin{array}{l}\text { Ploughing at } 30 \mathrm{~cm} \text {, } \\
\text { harrowing, } \\
\text { pre-planting puckering }\end{array}$ & $\begin{array}{l}\text { Ploughing at } 40 \mathrm{~cm} \text {, } \\
\text { harrowing (2) }\end{array}$ & $\begin{array}{l}\text { Ploughing at } 40 \mathrm{~cm} \text {, } \\
\text { harrowing (2) }\end{array}$ \\
\hline $\begin{array}{l}\text { Fertilisation, } \\
\mathrm{kg} / \mathrm{ha} \mathrm{N} \\
\mathrm{P}_{2} \mathrm{O}_{5}, \mathrm{~K}_{2} \mathrm{O}\end{array}$ & $\begin{array}{l}\text { Pre-sowing + } \\
\text { post-emergence } \\
150-120-0\end{array}$ & $\begin{array}{l}\text { Pre-sowing }+ \\
\text { post-emergence } \\
150-120-0\end{array}$ & $\begin{array}{l}\text { Pre-sowing + } \\
\text { post-emergence } \\
100-100-0\end{array}$ & $\begin{array}{l}\text { Pre-sowing + } \\
\text { post-emergence } \\
100-100-0\end{array}$ & $\begin{array}{l}\text { Pre-sowing } \\
80-200-200\end{array}$ & $\begin{array}{l}\text { Pre-sowing } \\
80-0-125\end{array}$ \\
\hline Sowing time & $12 / 4$ & $27 / 03$ & $12 / 04$ & $14 / 04$ & $25 / 03$ & $21 / 03$ \\
\hline
\end{tabular}

Table 6. Natural and artificial water supply during the crop cycle for the different cropping scenarios.

\begin{tabular}{|c|c|c|c|c|c|c|c|}
\hline Environment & Year & Thesis & $\begin{array}{l}\text { Number of } \\
\text { irrigations }\end{array}$ & $\begin{array}{l}\text { Irrigation water, } \\
\mathrm{mm}\end{array}$ & $\begin{array}{l}\text { Rainfall, } \\
\text { mm }^{\circ}\end{array}$ & $\begin{array}{l}\text { Total water received } \\
\text { by crops, } \mathrm{mm}\end{array}$ & $\begin{array}{l}\text { Groundwater } \\
\text { availability }\end{array}$ \\
\hline Udine & $\begin{array}{l}1999 \\
2000\end{array}$ & $\begin{array}{l}\text { Rain-fed } \\
\text { Irrigated } \\
\text { Rain-fed } \\
\text { Irrigated }\end{array}$ & $\begin{array}{c}6 \\
12 \\
2 \\
6\end{array}$ & $\begin{array}{c}52 \\
110 \\
70 \\
210\end{array}$ & $\begin{array}{l}1145 \\
1145 \\
1104 \\
1104\end{array}$ & $\begin{array}{l}1197 \\
1255 \\
1174 \\
1314\end{array}$ & $\begin{array}{l}\text { No } \\
\text { No } \\
\text { No } \\
\text { No }\end{array}$ \\
\hline Bologna & $\begin{array}{l}1999 \\
2000\end{array}$ & $\begin{array}{l}\text { Rain-fed } \\
\text { Irrigated } \\
\text { Rain-fed } \\
\text { Irrigated }\end{array}$ & $\begin{array}{c}0 \\
12 \\
0 \\
11\end{array}$ & $\begin{array}{c}0 \\
318 \\
0 \\
361\end{array}$ & $\begin{array}{l}516 \\
516 \\
410 \\
410 \\
\end{array}$ & $\begin{array}{l}516 \\
834 \\
410 \\
771\end{array}$ & $\begin{array}{l}\text { Yes } \\
\text { Yes } \\
\text { Yes } \\
\text { Yes }\end{array}$ \\
\hline Bari & $\begin{array}{l}1999 \\
2000\end{array}$ & $\begin{array}{l}\text { Rain-fed } \\
\text { Irrigated } \\
\text { Rain-fed } \\
\text { Irrigated }\end{array}$ & $\begin{array}{l}14 \\
14 \\
11 \\
11\end{array}$ & $\begin{array}{l}143 \\
570 \\
115 \\
451\end{array}$ & $\begin{array}{l}237 \\
237 \\
403 \\
403\end{array}$ & $\begin{array}{l}380 \\
807 \\
518 \\
854\end{array}$ & $\begin{array}{l}\text { Yes } \\
\text { Yes } \\
\text { Yes } \\
\text { Yes }\end{array}$ \\
\hline
\end{tabular}

${ }^{\circ}$ Rainfall period: March-October. 
represent the maximum yields in biomass satisfactorily. In some cases, the irrigation in the trials had a very limited effect on the biomass yield; this has also been well reproduced by the simulation (Figure 6). In these environments, in fact, the effect of the irrigation regime was very limited owing to the favourable climatic conditions, good soil characteristics or shallow water table.

Table 7 shows some statistical indices (root mean square error RMSE, modelling efficiency EF, coefficient of determination CD, coefficient residual mass CRM and maximum absolute error MaxAE) for the model calibration (Janssen and Heuberger, 1995) for the different growing areas, thesis and crop seasons, obtained by the SEMoLa
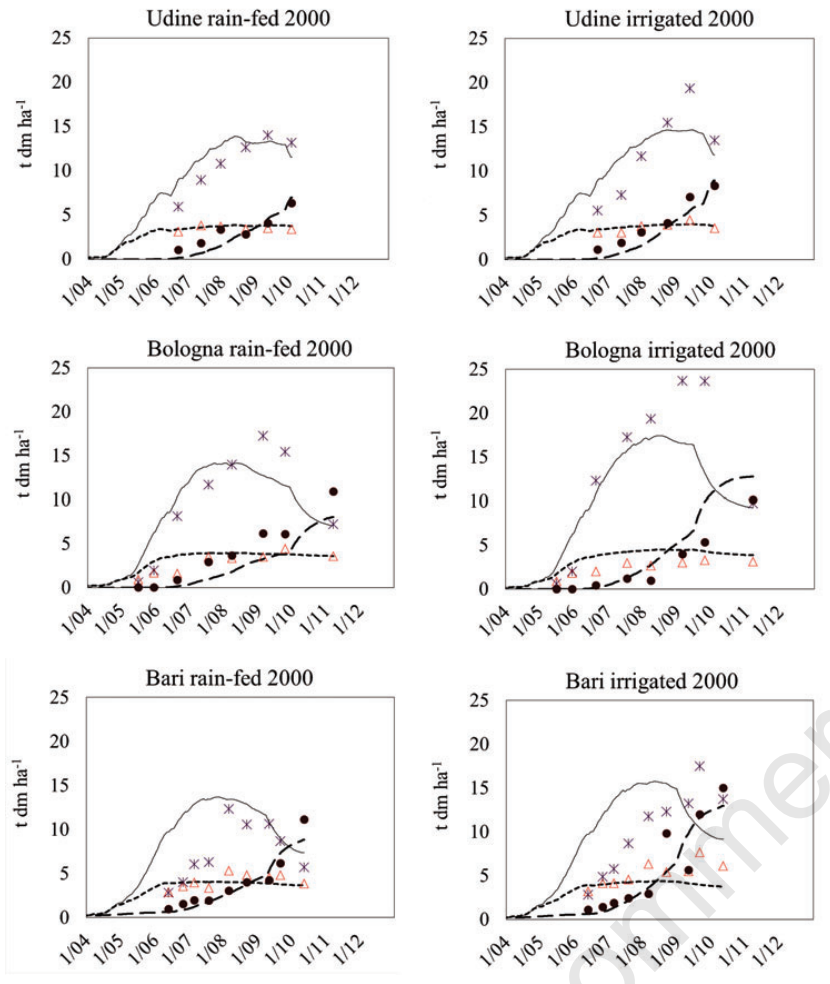

Figure 5. Leaves, stalks and storage organs biomass accumulation, as simulated by the Cropping System Simulator, in comparison with the experimental growth data for the three locations and the two irrigation regimes (year 2000). stems d.m. weight simulated; ---- leaves d.m. weight simulated; _ _ _ storage organs d.m. weight simulated; * stems d.m. weight measured; $\Delta$ leaves $\mathrm{d} . \mathrm{m}$. weight measured; • storage organs d.m. weight measured.

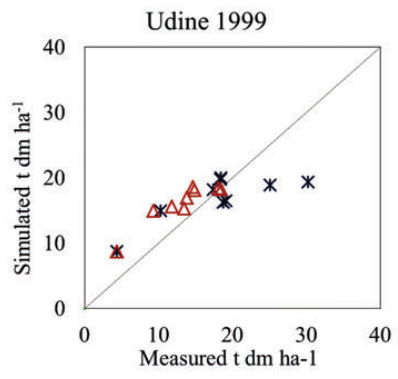

*irrigated $\mathrm{S}=0.3831 \cdot \mathrm{M}+10.074 \quad \mathrm{R}^{2}=0.6505$ $\Delta$ rain-fed $\mathrm{S}=0.6606 \cdot \mathrm{M}+7.3975 \quad \mathrm{R}^{2}=0.851$

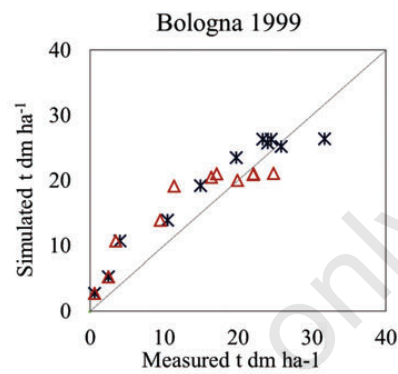

*irrigated $\mathrm{S}=0.8158 \cdot \mathrm{M}+5.1833 \quad \mathrm{R}^{2}=0.9327$ $\triangle$ rain-fed $\mathrm{S}=0.7281 \cdot \mathrm{M}+6.1010 \quad \mathrm{R}^{2}=0.8423$

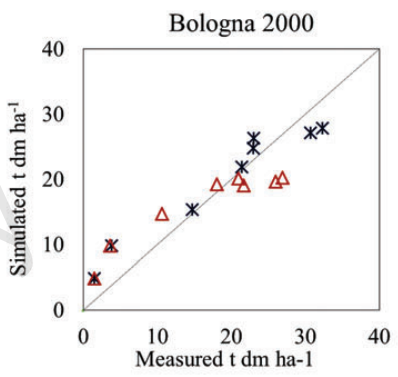

*irrigated $\mathrm{S}=0.747 \cdot \mathrm{M}+5.7036 \quad \mathrm{R}^{2}=0.9454$ $\triangle$ rain-fed $\mathrm{S}=0.5554 \cdot \mathrm{M}+6.9801 \mathrm{R}^{2}=0.8887$
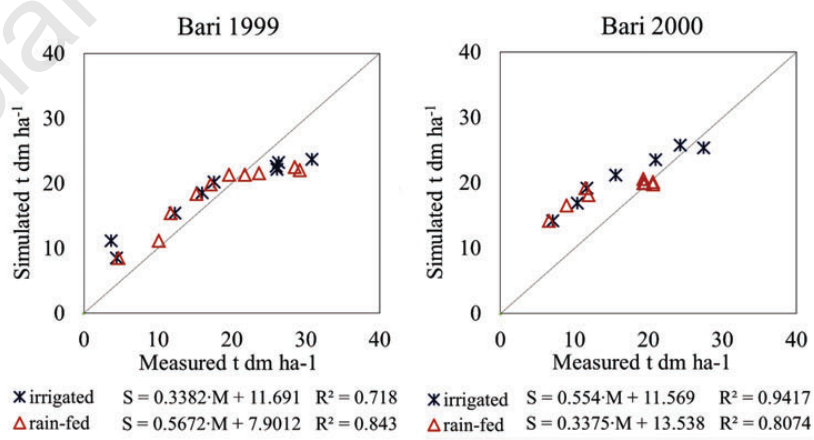

*irrigated $\mathrm{S}=0.554 \cdot \mathrm{M}+11.569 \quad \mathrm{R}^{2}=0.9417$ $\Delta$ rain-fed $\quad \mathrm{S}=0.3375 \cdot \mathrm{M}+13.538 \quad \mathrm{R}^{2}=0.8074$

Figure 6. Total biomass accumulation obtained by simulations, in comparison with data measured for irrigated and rain-fed Jerusalem artichoke, at Udine, Bologna and Bari, for the two years.

Table 7. Model calibration statistics of comparison of simulated and observed data for irrigated and rain-fed Jerusalem artichoke at Udine, Bologna and Bari, for the two years (total biomass).

\begin{tabular}{|c|c|c|c|c|c|c|c|}
\hline Environment & Year & Thesis & $\begin{array}{c}\text { RMSE, } \\
\text { t/ha }\end{array}$ & $\begin{array}{c}\text { EF } \\
-\end{array}$ & $\begin{array}{c}C D \\
-\end{array}$ & $\begin{array}{c}\text { CRM } \\
-\end{array}$ & $\begin{array}{c}\text { MaxAE, } \\
\text { t/ha }\end{array}$ \\
\hline Udine & $\begin{array}{l}1999 \\
2000\end{array}$ & $\begin{array}{l}\text { Irrigated } \\
\text { Rain-fed } \\
\text { Irrigated } \\
\text { Rain-fed }\end{array}$ & $\begin{array}{l}4.88 \\
3.43 \\
3.40 \\
1.54\end{array}$ & $\begin{array}{l}0.52 \\
0.30 \\
0.79 \\
0.87\end{array}$ & $\begin{array}{l}0.25 \\
1.02 \\
0.35 \\
0.69\end{array}$ & $\begin{array}{c}0.06 \\
-0.22 \\
0.00 \\
-0.07\end{array}$ & $\begin{array}{l}10.87 \\
5.66 \\
6.30 \\
2.97\end{array}$ \\
\hline Bologna & $\begin{array}{l}1999 \\
2000\end{array}$ & $\begin{array}{l}\text { Irrigated } \\
\text { Rain-fed } \\
\text { Irrigated } \\
\text { Rain-fed }\end{array}$ & $\begin{array}{l}3.62 \\
4.18 \\
3.43 \\
4.46\end{array}$ & $\begin{array}{l}0.87 \\
0.74 \\
0.90 \\
0.76\end{array}$ & $\begin{array}{l}0.76 \\
0.71 \\
0.60 \\
0.35\end{array}$ & $\begin{array}{l}-0.13 \\
-0.18 \\
-0.05 \\
0.01\end{array}$ & $\begin{array}{l}6.63 \\
7.81 \\
5.97 \\
6.69\end{array}$ \\
\hline Bari & $\begin{array}{l}1999 \\
2000\end{array}$ & $\begin{array}{l}\text { Irrigated } \\
\text { Rain-fed } \\
\text { Irrigated } \\
\text { Rain-fed }\end{array}$ & $\begin{array}{l}9.35 \\
3.76 \\
5.25 \\
4.92\end{array}$ & $\begin{array}{l}0.48 \\
0.75 \\
0.45 \\
0.13\end{array}$ & $\begin{array}{l}0.19 \\
0.38 \\
0.66 \\
0.55\end{array}$ & $\begin{array}{l}0.11 \\
0.00 \\
-0.24 \\
-0.22\end{array}$ & $\begin{array}{l}7.49 \\
7.17 \\
7.45 \\
7.71\end{array}$ \\
\hline
\end{tabular}

RMSE, root mean square error; EF, modelling efficiency; CD, coefficient of determination; CRM, coefficient residual mass; MaxAE, maximum absolute error. 
framework. The lowest limit of RMSE is 0 , that means full adherence between model estimates and measures. The use of $\mathrm{EF}$ is an extension to any class of models of the common $\mathrm{R}^{2}$ statistics of regression lines. EF can have either positive or negative values, 1 being the upper limit, while negative infinity is the theoretical lower bound. CD is the proportion of total variance of measurements explained by the estimates but it is not the same as $\mathrm{R}^{2}$, being possible values of $\mathrm{CD}$ greater than $1(C D=1$ is the best; that is, the deviation from the mean of measurements is the same for estimates and measurements). MaxAE is most sensitive to outliers, and in fact is the worst case measure. The indices MaxAE and CRM can be either positive or negative, zero being the optimal value.

\section{Discussion and Conclusions}

The capability of the CSS model to represent well the experimental results on Jerusalem artichoke obtained in very different environmental and agronomic conditions (from northern to southern Italy) suggests its usefulness as a tool for the planning and risk evaluation of introducing Jerusalem artichoke as a crop for energy or inulin production. The model, despite a simplified description of some processes (e.g. soil water dynamics), seems to be adequately responsive to the main environmental factors causing yield and biomass production variation among years and locations.

Indeed, the simulations confirm, at least for the yield in total biomass, the possibility of using the model to evaluate the different crop management techniques and Italian pedo-climatic conditions, even if the model has been developed primarily to simulate annual herbaceous crops and yielding seeds but not tubers and stalks as in the case of Jerusalem artichoke. However, further model improvements are necessary in order to better represent phenology, partitioning and translocation of the assimilates among the plant organs. In particular, the source-sink relationship between stalk and tuber during the development phases of the plant and in different environments will have to be clarified better and modelled. In fact, the tubers are grown by both current photosynthates and remobilisation of reserves from other plant parts, mainly from the stalk. The transfer from stalk to tuber is known to be up to $50 \%$ of final tuber dry weight, depending on many factors: temperatures, flowering time of the cultivar, aerial structural growth, tuber sink capacity, with complicated competing sinks, at plant level, and with changing hierarchical relations during the crop cycle (Denoroy, 1996). Efforts have to be made to understand better the mechanism of distribution of assimilates among aerial structures and tubers, in order to identify the optimal period to obtain the maximum biomass yield, adopting an integral or an aerial harvest, within the perspective of considering Jerusalem artichoke as a crop for producing raw material for energy use at competitive prices.

In conclusion, CSS allows several aspects related to the cropping system to be simulated. However, it is necessary to calibrate the model for each specific crop. Moreover, the development of a more detailed crop parameter database is desirable for further evaluation and improvement of the model for crops with high translocation of assimilates. CSS is also a fundamental part of the farming system simulation X-Farm model (Danuso et al., 2010) where, using new concepts, it can be run automatically for any number of fields on a farm.

\section{References}

Allen R.G., Pereira L.S., Raes D., Smith M., 1998. Crop evapotranspiration guidelines for computing crop water requirements. FAO Irrigation and Drainage paper 56. Food and Agriculture Organization of the United
Nations, Rome, Italy.

Baldini M., Danuso F., Monti A., Amaducci M.T., Stevanato P., De Mastro G., 2006. Chicory and Jerusalem artichoke productivity in different areas in Italy, in relation to water availability and time of harvest. Ital. J. Agron. 1:291-309.

Baldini M., Danuso F., Turi M., Vannozzi G.P., 2004. Evaluation of new clones of Jerusalem artichoke (Helianthus tuberosus L.) for inulin and sugar yield from stalks and tubers. Ind. Crops Prod. 19:25-40.

Beck J.V., Arnold K.J., 1977. Parameter Estimation in Engineering and Science. Wiley \& Sons, New York, NY, USA.

Coleman K., Jenkinson D.S., 2008. ROTHC-26.3. A model for the turnover of carbon in soil. Model description and windows users' guide. Rothamsted Research, Harpenden, Herts, UK.

Curt M.D., Aguado P., Sanz M., Sànchez G., Fernàndez J., 2006. Clone precocity and the use of Helianthus tuberosus L. stems for bioethanol. Ind. Crops Prod. 24:314-320.

Danuso F., 2001. Le colture per la produzione di inulina: attualità e prospettive. Inform. Agr. 3:176-187.

Danuso F., 2003. SEMoLa: uno strumento per la modellizzazione degli agroecosistemi. Pages 283-284 in Atti XXXV Congresso Società Italiana di Agronomia, Napoli, Italy.

Danuso F., Franz D., Bigot L., Budoi G., 1999. CSS: a modular software for cropping system simulation. pp 287-288 in Proc. Int. Symp. Modelling cropping systems, ESA, Lleida, Spain.

Danuso F., Rocca A., Andreoni V., Bulfoni E., 2010. Simulation of the agroenergy farm with the X-farm model: calibration of the crop module for sorghum yield. Ital. J. Agron. 5:275-284.

Danuso F., Rocca A., Bulfoni E., Zuliani F., Barbanti L., Monti A., Bonari E., Tozzini C., Cosentino S., Copani V., 2009. Studio del Comportamento del Sorgo da Biomassa in Diversi Scenari Colturali Italiani con il Modello CSS. Pages 231-232 in Atti XXXVIII Congresso Società Italiana di Agronomia, Firenze, Italia.

Danuso F., Sandra M., 2006. Climatica: un software per la gestione ed elaborazione delle informazioni climatiche. Riv. Ital. Agrometeorol. 2:26-33.

D’Egidio M.G., Cecchini C., Cervigni T., Donini B., Pignatelli V., 1998. Production of fructose from cereal stems and polyannual cultures of Jerusalem artichoke. Ind. Crops Prod. 7:113-119.

Denoroy P., 1996. The crop physiology of Helianthus tuberosus L.: a model orientated view. Biomass Bioenerg. 11:11-32.

Draper N.R., Smith H., 1981. Applied Regression Analysis. 2nd ed. Wiley \& Sons, New York, NY, USA.

Driessen P.M., Konijn N.T., 1992. Land-use systems analysis. Department of Soil Science \& Geology, Wageningen Agricultural University Ed., Waningen, The Netherlands.

Encinar J.M., Gonzalez J.F., Martinez G., Roman S., 2009. Jerusalem artichoke pyrolysis: energetic evaluation. J. Anal. Appl. Pyrolysis 85:294 300 .

Fuchs A. 1993. Inulin and inulin containing crops. Studies in Plant Science, Vol. 3. Elsevier, Amsterdam, The Netherlands.

Janssen P.H.M., Heuberger P.S.C., 1995. Calibration of process oriented models. Ecol. Modelling 83:55-66.

Lehtomäki A., Viinikainen T., Rintala J., 2008. Screening boreal energy crops and crop residues for methane biofuel production. Biomass Bioenerg. 32:541-550.

Paolini R., Del Puglia S., Abbate V., Copani V., Danuso F., De Mastro G., Losavio N., Marzi V., Molfetta P., Pignatelli V., Venezia G., Vonella A.V., 1996. Produttività del topinambur (Helianthus tuberosus L.) in relazione a fattori agronomici diversi. Agricoltura Ricerca 163:126-144.

van Laar H.H., Goudriaan J., van Keulen, H., 1997. SUCROS97: Simulation of crop growth for potential and water-limited production situations. Quantitative approaches in systems analysis No. 14. AB-DLO Ed., Wageningen, The Netherlands. 